\title{
Body temperature maintenance acclimates in a winter-tenacious songbird
}

\author{
Maria Stager ${ }^{1}$, Nathan R. Senner ${ }^{2}$, Bret W. Tobalske ${ }^{1}$, and Zachary A. Cheviron ${ }^{1}$ \\ ${ }^{1}$ Division of Biological Sciences, University of Montana, Missoula, MT, USA \\ ${ }^{2}$ Department of Biological Sciences, University of South Carolina, Columbia, SC, USA
}

\begin{abstract}
Flexibility in heat generation and dissipation mechanisms provides endotherms the ability to match their thermoregulatory strategy with external demands. However, the degree to which these two mechanisms account for seasonal changes in body temperature regulation is unexplored. Here we present novel data on the regulation of avian body temperature to investigate how birds alter mechanisms of heat production and heat conservation to deal with variation in ambient conditions. We subjected Dark-eyed Juncos (Junco byemalis) to chronic cold acclimations of varying duration and subsequently quantified their metabolic rates, thermal conductance, and ability to maintain normothermia. Cold-acclimated birds adjusted traits related to both heat generation (increased summit metabolic rate) and heat conservation (decreased conductance) to improve their body temperature regulation. Increases in summit metabolic rate occurred rapidly, but plateaued after one week of cold exposure. In contrast, changes to conductance occurred only after nine weeks of cold exposure. Thus, the ability to maintain body temperature continued to improve throughout the experiment, but the mechanisms underlying this improvement changed through time. Our results demonstrate the ability of birds to adjust thermoregulatory strategies in response to thermal cues and reveal that birds may combine multiple responses to meet the specific demands of their environments.
\end{abstract}

\section{INTRODUCTION}

Body temperature $\left(\mathrm{T}_{\mathrm{b}}\right)$ influences all aspects of animal function, from the rate of chemical reactions to metabolism, growth, and locomotion. Endogenous heat generation allows homeothermic endotherms to maintain a relatively constant $\mathrm{T}_{\mathrm{b}}$ across a broad range of environmental temperatures, thereby providing physiological advantages (Bennett and Ruben, 1979; Crompton et al., 1978) that have enabled them to occupy a wide variety of habitats and climates. To maintain this high internal temperature, homeothermic endotherms coordinate changes occurring at multiple hierarchical levels of biological organization to respond to fluctuations in their environment.

The demands of $\mathrm{T}_{\mathrm{b}}$ regulation are especially pronounced in temperate biomes where climates are often cooler than endothermic $\mathrm{T}_{\mathrm{b}}$. Winter, in particular, can impose large temperature differentials for resident endotherms, and this thermoregulatory challenge is layered on top of other stresses, including reduced food availability, decreased daylight for foraging, and long nights of fasting (Marsh and Dawson, 1989). Unlike mammals that hibernate, a wide variety of birds remain active in temperate biomes all winter (Swanson, 2010). Some birds make use of heat-conservation mechanisms to cope with these conditions, such as huddling and utilizing microclimatic refugia, or employ facultative heterothermia, thereby decreasing their temperature differential with the environment and reducing energy consumption (Douglas et al., 2017; Korhonen, 1981; Mckechnie and Lovegrove, 2002). In spite of the benefits of these mechanisms, birds still need to eat, and they can frequently be seen foraging on even the most blustery days. 
To remain active throughout the temperate winter, birds employ two primary physiological strategies to achieve normothermia. First, they can increase heat production. In general, avian thermogenesis results from shivering (Marsh and Dawson, 1989) or as a by-product of metabolism and activity (Dawson and O'Connor, 1996), although the role of non-shivering thermogenesis in adult birds is not well characterized (Hohtola, 2002). Peak oxygen consumption under cold exposure (summit metabolic rate; $\mathrm{M}_{\text {sum }}$ ) is often used as a proxy for thermogenic capacity, and many birds have been shown to increase $\mathrm{M}_{\text {sum }}$ by $10-50 \%$ in winter (Swanson, 2010). These seasonal changes have been credited with higher heat production and increased cold tolerance (O'Connor, 1995; Swanson, 1990a). At the same time, fueling an elevated metabolic rate requires increased foragingand thus concomitantly escalates exposure to predators (Lima, 1985) - in addition to the potential energetic cost of restructuring internal physiology to meet these heightened aerobic demands (Liknes and Swanson, 2011). Few studies, however, have fully explored these potential trade-offs in natural systems (but see Petit et al., 2017), and shivering thermogenesis is frequently thought to represent the major mechanism by which birds maintain normothermia in winter (Swanson, 2010). Nonetheless, improved cold tolerance can occur independent of increases in $\mathrm{M}_{\text {sum }}$ (Dawson and Smith, 1986; Saarela et al., 1989), indicating additional strategies may be employed.

For small passerines that have high surface to volume ratios, seasonal decreases in thermal conductance (i.e. the transport of energy across a temperature gradient) may also be favored by natural selection. Direct measures of heat transfer are scarce (Wolf and Walsberg, 2000), but indirect measures indicate that thermal conductance decreases with decreasing ambient temperature across avian taxa (Londoño et al., 2017), which may be associated with increases in plumage density (Osváth et al., 2018). However, the role of seasonal adjustments to thermal conductance in birds is not well understood. Although some birds increase plumage mass in winter (Møller, 2015), it is unclear how this is achieved: most passerines molt only once per year, and their winter feathers are thus also their eventual summer feathers. Birds could also make behavioral adjustments in the cold, including postural changes to reduce surface area-especially of unfeathered areas, like the head and feet (Ferretti et al., 2019)—or erecting feathers to trap air around the body (Morris, 1956). Given these knowledge gaps, the question remains: what are the relative contributions of heat conservation and heat generation processes to avian body temperature regulation in the cold?

Such questions are particularly important in this era of rapid climatic change. Although ambient conditions can vary predictably, recent increases in climatic variability (e.g., Kolstad et al., 2010) highlight the need for animals to respond rapidly to changing conditions. Each of the aforementioned potential physiological responses is likely tied to different environmental cuesprimarily photoperiod and temperature (Swanson \& Vézina, 2015). However, we do not understand how birds respond to environmental stimuli to balance heat loss and heat production, which is vital to projections of endothermic distributions under predicted future climate change scenarios (Buckley et al., 2018).

To understand how birds modify their thermoregulatory ability in the cold, we performed an acclimation experiment using Dark-eyed Juncos (Junco byemalis). Juncos are small songbirds that overwinter across much of North America and are not known to huddle or use torpor (Nolan, Jr. et al., 2002). We exposed juncos sampled from a single population to one of ten experimental treatments that varied in temperature and the duration of cold exposure. Following acclimation to these experimental treatments, we quantified metabolic rates, heat loss across the skin and plumage, and $T_{b}$ maintenance within the same individuals. Our results shed light on the ability of birds to respond to thermal cues and elucidate the mechanisms underlying their physiological responses to cold temperatures. 


\section{MATERIALS AND METHODS}

\section{Acclimation experiments}

We captured adult juncos breeding in Missoula County, Montana, USA $\left(\sim 47.0^{\circ} \mathrm{N},-113.4^{\circ} \mathrm{W}\right)$ from 12-19 July $2016(n=56)$ using mist nets. To increase sample sizes, we captured additional individuals 27 July - 3 August $2017(n=52)$ and repeated all procedures. We immediately transferred birds to husbandry facilities at the University of Montana and housed them individually under common conditions for 42 days $\left(18^{\circ} \mathrm{C}, 10 \mathrm{~h}\right.$ light : $14 \mathrm{~h}$ dark). After this six-week adjustment period, we assayed metabolic rates (see below). Following metabolic trials, we allowed birds to recover for $\sim 24 \mathrm{hrs}$ before we randomly assigned individuals to acclimation groups and subjected them to one of two temperature treatments, Cold $\left(-8^{\circ} \mathrm{C}\right)$ or Control $\left(18^{\circ} \mathrm{C}\right)$, lasting $7 \mathrm{~d}$ (Week 1), $14 \mathrm{~d}$ (Week 2$), 21$ $\mathrm{d}$ (Week 3), $42 \mathrm{~d}$ (Week o), or $63 \mathrm{~d}$ (Week 9) in duration. We chose to acclimate birds to $-8^{\circ} \mathrm{C}$, which is a temperature that juncos experience in the northern parts of their winter range for weeks at a time (Fig. S1) and which could elicit more dramatic physiological responses than previous experiments with juncos performed at $3{ }^{\circ} \mathrm{C}$ (Swanson et al., 2014). Photoperiod was maintained at a constant 10L: 14D in both treatments (the photoperiod in Missoula County in November and February), and food and water were supplied ad libitum for the duration of the experiment. Birds were fed white millet and black oil sunflower seeds at a 2:1 ratio by weight, supplemented with ground dog food, live mealworms, and vitamin drops (Wild Harvest D13123 Multi Drops) in their water. We did not repeat the Week 9 treatment in 2017. Also, one individual died 12 days into the Cold treatment in 2016 and another died during the adjustment period in 2017 (causes unknown), resulting in a total sample size of 106 individuals $\left(n=12\right.$ per treatment, except $n_{\text {Control_1 }}=11, n_{\text {Control_9 }}=$ $\left.6, n_{\text {Cold_ } 9}=5\right)$.

As an index of body size, we measured the tarsus lengths ( $\mathrm{mm})$ of both legs and calculated the average measure for each individual. We quantified this feature only once (after the bird was euthanized) assuming that tarsus length did not change over the duration of the acclimation because all individuals were adults. The sample is heavily male-biased $(90.5 \%)$ but includes 10 females $(9.5 \%)$ across the two years. These females were randomly distributed across most treatment groups (Table S1). Brood patches and cloacal protuberances were not present after the six-week adjustment period. Sex was confirmed post-acclimation by identification of the gonads during dissection. For five additional males captured at the same time but not included in the study, we confirmed by dissection that testes had regressed before the acclimations began.

\section{Metabolic assays}

We measured resting metabolic rate (RMR) and $\mathrm{M}_{\text {sum }}$ in a temperature-controlled cabinet using open-flow respirometry before and after acclimation treatments. RMR trials were conducted in the evening during birds' dark cycle (start time $\mu=19: 11$; range $=18: 00-23: 20$ ). $\mathrm{M}_{\text {sum }}$ trials were conducted the following day largely within birds' light cycle (start time $\mu=13: 30$; range $=09$ :00 20:42). Birds were not fasted before either measurement so as not to limit aerobic performance and to ease comparison between measures. For RMR trials, birds were placed in a modified 1-L Nalgene container and measured in a dark, quiet temperature cabinet (Sable Systems Pelt Cabinet with Pelt-5 Temperature Controller) at $27^{\circ} \mathrm{C}$, which is within the thermoneutral zone of juncos (Swanson, 1991). Three individuals were assayed simultaneously. We cycled through individuals at 15-min intervals alternated with 5-min ambient baseline measures, such that each individual was measured for at least 30 minutes over the course of 2 hours. We subjected an individual to additional rounds of measurement if the $\mathrm{O}_{2}$ trace suggested that it was active. Ambient air was first dried (using drierite), pumped through the animal chamber at $500 \mathrm{ml} / \mathrm{min}$, and excurrent air was subsampled manually from one chamber at a time at $100-150 \mathrm{ml} / \mathrm{min}$ through barrel syringes. We dried 
excurrent air again, then $\mathrm{CO}_{2}$ was scrubbed with ascarite, and the outflow dried again before passing through a FoxBox (Sable Systems) to quantify $\mathrm{O}_{2}$. The same setup was used for both baseline and animal chambers. We spanned the FoxBox using baseline air at 20.95\% $\mathrm{O}_{2}$ before each trial began. Flow was controlled using a mass flow meter (Sable Systems). From these measures, we quantified oxygen consumption according to Lighton (2008). We first corrected for any fluctuations in baseline concentrations then calculated RMR as the lowest oxygen consumption $\left(\mathrm{ml} \mathrm{O}_{2} \bullet \mathrm{min}^{-1}\right)$ averaged over a ten-minute period using custom scripts in the $\mathrm{R}$ programming environment ( $\mathrm{R}$ Core Team, 2018).

$\mathrm{M}_{\text {sum }}$ trials were conducted using a similar setup with static cold exposure. Trials were conducted in a heliox environment (21\% helium, $79 \%$ oxygen) with flow rates of $750 \mathrm{ml} / \mathrm{min}$. The high thermal conductance of heliox facilitates heat loss at higher temperatures than is necessary in air to avoid injury to experimental subjects (Rosenmann and Morrison, 1974). Heliox flow rates were measured using a mass flow meter (Alicat M-series) programmed for the specific gas mixture. Pre-acclimation $\mathrm{M}_{\text {sum }}$ trials were conducted using the above temperature cabinet set to $-5^{\circ} \mathrm{C}$. Trials ended when a bird's $\mathrm{CO}_{2}$ production plateaued or after one hour, whichever came first. Immediately upon removing birds from the temperature cabinet, we measured body temperature using a thermistor probe inserted into the cloaca. We considered birds hypothermic if their body temperature was $\leq 37^{\circ} \mathrm{C}$ (per Swanson et al., 2014). One individual that was not hypothermic at the end of the $\mathrm{M}_{\text {sum }}$ trail was removed from further analysis. We corrected for drift then calculated $\mathrm{M}_{\text {sum }}$ as the highest oxygen consumption $\left(\mathrm{ml} \mathrm{O}_{2} \bullet \mathrm{min}^{-1}\right)$ averaged over a five-minute period using custom scripts in R. As a measure of thermogenic endurance, we calculated the number of minutes that an individual maintained $90 \%$ or more of their $\mathrm{M}_{\text {sum }}$ (Cheviron et al., 2013).

Because we expected acclimated birds to differ in their cold tolerance, we performed postacclimation $\mathrm{M}_{\text {sum }}$ trials at lower temperatures for cold acclimated birds (starting cabinet temperature $\mu=-24.47 \pm 2.87)$ than control acclimated birds $(\mu=-15.94 \pm 5.98)$ using a laboratory freezer (Accucold VLT650). These temperatures, concurrent with a heliox atmosphere, represent rather severe conditions that juncos are unlikely to encounter in the wild but were chosen because previous work has demonstrated that cold exposure in excess of $-9^{\circ} \mathrm{C}$ in heliox is necessary to induce hypothermia within 90 minutes in winter acclimatized juncos (Swanson, 1990a). Although we aimed for static cold exposure, logistical constraints did not allow for precise temperature control. We thus recorded temperature inside the cabinet for the duration of the trial to account for variation within and among trials. Post-acclimation trials ended after an extended period of declining $\mathrm{CO}_{2}$ production coincident with the bird's body temperature dropping below $30^{\circ} \mathrm{C}$ (see below).

We used multiple respirometry setups in order to complete all pre-acclimation measurements precisely 42 d after the day of capture (three units in 2016, four in 2017). Post-hoc tests revealed significant differences in the metabolic measurements made by each respirometry unit. To control for these effects, we regressed each metabolic trait $\left(\mathrm{RMR}\right.$ or $\left.\mathrm{M}_{\text {sum }}\right)$ on respirometry unit for each year and then subtracted the resulting beta coefficient (slope) from the metabolic rate (Table S2). Although all post-acclimation measures were conducted using a single respirometer, we used the same correction factor to make the before and after measures comparable. In a few instances, this resulted in negative $\mathrm{M}_{\text {sum }}$ values that were removed from further analysis $(n=3$ pre-acclimation measures, $n=1$ post-acclimation). Metabolic trials for cold individuals were conducted earlier in the day than those of control individuals because the temperature cabinet tended to increase in temperature each time it was opened. For this reason, we tested for but did not find a significant interaction between trial start time and temperature treatment on post-acclimation $\mathrm{M}_{\text {sum }}(p=0.21)$.

We measured body mass $\left(\mathrm{M}_{\mathrm{b}}\right.$; in $\left.\mathrm{g}\right)$ immediately before each metabolic assay. Birds were banded with a unique combination of two or three plastic leg bands; the mass of these bands has been removed from all reported $\mathrm{M}_{\mathrm{b}}$. Directly following the post-acclimation $\mathrm{M}_{\text {sum }}$ trial, we 
euthanized individuals using cervical dislocation, removed organs and tissues within the body cavity, filled the body cavity with a wet paper towel to preserve moisture, and froze carcasses at $-20^{\circ} \mathrm{C}$ until thermal conductance assays were performed in May and June 2019. To quantify the change in each trait value with acclimation, we subtracted an individual's pre-acclimation trait value from their postacclimation value $\left(\Delta \mathrm{M}_{\mathrm{b}}, \Delta \mathrm{RMR}\right.$, and $\left.\Delta \mathrm{M}_{\text {sum }}\right)$. We did not compare endurance measures pre- and post-acclimation because trial conditions varied before and after acclimation.

\section{Thermal conductance assays}

We measured the conductive properties of the skin and plumage by quantifying the amount of power input $(\mathrm{mW})$ required to maintain a constant internal temperature of $39^{\circ} \mathrm{C}$ with the ambient temperature providing a gradient. To do this, we first thawed carcasses at room temperature and dried the feathers. We removed any adipose or muscle tissue remaining in the body cavity, then inserted an epoxy mold ( $35 \mathrm{~mm}$ long x $16 \mathrm{~mm}$ in diameter; PC-Marine Epoxy Putty) into the coelom that we designed to fill the coelom without significant stretching of the superficial thoracic and abdominal regions. Within this mold, we embedded a centrally placed thermocouple and a length of nichrome wire for heating. These were connected to a custom-made board containing a Voltage logger (Omega OM-CP-Quadvolt), an amperage logger (Omega OM-CP-Process 101A-3A), and a temperature controller (Omega CNI1622-C24-DC). Power was supplied to the circuit using a 12V DC battery. We sewed the body cavity together using sewing thread, leaving a small hole near the cloaca for the wires to exit. We suspended the carcass from a single thread through the nares, supported by the wires from below, such that birds were in an upright position with legs hanging freely. We cleaned the feathers with cornmeal to remove oils and combed the feathers into place. Wings were positioned at the sides, tucked in as best as possible. We removed 6 carcasses damaged beyond repair in post-processing.

Conductance trials were conducted in a small, closed room without airflow and at ambient (laboratory) temperature $(\boldsymbol{\mu}=23.4 \pm 0.61)$. The mold was first brought to $39^{\circ} \mathrm{C}$ and power was supplied whenever the temperature dropped below $38^{\circ} \mathrm{C}$. We recorded the amperage, Voltage, and temperature of the thermocouple for each second of an eighteen-minute trial. We calculated the average power input (conductance, $\mathrm{mW}$ ) as the mean Volts $\times$ amps over a ten-minute period. We excluded two individuals for which temperatures did not stay within the specified range, resulting in a total sample size of $n=98$. All assays were performed by a single individual (MS) and were done blind to the birds' treatment assignments. We did not find a significant effect of the minor variation in ambient temperature that occurred on average power input using a linear regression $(p=0.19)$. Trials were performed across multiple days, but we did not find an effect of measurement day (Table S3) or freeze duration on average power input $(p=0.95)$.

\section{Body temperature maintenance}

To quantify the ability to maintain normothermia during acute cold exposure, we measured $\mathrm{T}_{\mathrm{b}}$ continuously for the duration of the post-acclimation $\mathrm{M}_{\text {sum }}$ acute cold trial. Immediately prior to this trial, we inserted a temperature-sensitive passive integrated transponder (PIT) tag (12mm, Biomark) into the cloaca of the bird. PIT tags were inserted at room temperature; thus, even Cold birds were exposed to warmer conditions for a few minutes preceding the $\mathrm{M}_{\text {sum }}$ trial. To secure the tag, we glued the feathers surrounding the cloaca together using cyanoacrylate adhesive (super glue). We quantified $\mathrm{M}_{\mathrm{b}}$ before the addition of the PIT tag. An antenna was placed inside the temperature cabinet next to the animal chamber and connected to an external reader that recorded $\mathrm{T}_{\mathrm{b}}$ eight times 
Table 1. Linear effects of Cold treatment and Duration on phenotypic traits before and after acclimation. Mass $\left(\mathrm{M}_{\mathrm{b}}\right)$ is included as a covariate for metabolic traits. Delta $(\Delta)$ represents change over acclimation period (postminus pre-acclimation) for traits that were measured at both time points. Bolded significant effects after Bonferroni correction for multiple models $(\mathrm{p}<0.004)$.

\begin{tabular}{|c|c|c|c|c|c|c|c|c|c|c|c|c|c|c|}
\hline \multirow{2}{*}{\multicolumn{2}{|c|}{ Phenotype }} & \multirow[b]{2}{*}{$n$} & \multicolumn{2}{|c|}{ Intercept } & \multicolumn{3}{|c|}{$\mathrm{M}_{\mathrm{b}}$} & \multicolumn{3}{|c|}{ Cold Treatment } & \multicolumn{3}{|c|}{ Duration } & \multirow{2}{*}{$\begin{array}{l}\text { Adj. } \\
\mathrm{R}^{2}\end{array}$} \\
\hline & & & $\beta$ & SE & $\beta$ & SE & $p$ & $\beta$ & SE & $p$ & $\beta$ & SE & $\mathrm{p}$ & \\
\hline \multirow{5}{*}{ 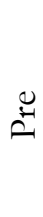 } & $\mathrm{M}_{\mathrm{b}}$ & 106 & 22.34 & 0.31 & & & & 0.02 & 0.31 & 0.94 & -0.05 & 0.06 & 0.41 & -0.01 \\
\hline & Tarsus & 106 & 19.91 & 0.11 & & & & 0.10 & 0.11 & 0.33 & 0.04 & 0.02 & 0.07 & 0.02 \\
\hline & RMR & 106 & 0.28 & 0.31 & 0.05 & 0.01 & $8.9 \times 10^{-4}$ & -0.01 & 0.04 & 0.82 & -0.01 & 0.01 & 0.13 & 0.10 \\
\hline & $\mathrm{M}_{\text {sum }}$ & 102 & 4.90 & 0.79 & 0.06 & 0.04 & 0.07 & 0.10 & 0.12 & 0.40 & -0.01 & 0.02 & 0.52 & 0.02 \\
\hline & Endur. & 103 & 37.56 & 18.20 & -0.48 & 0.81 & 0.55 & 1.52 & 2.76 & 0.58 & 0.05 & 0.55 & 0.93 & -0.02 \\
\hline \multirow{6}{*}{$0_{0}^{0}$} & $\mathrm{M}_{\mathrm{b}}$ & 106 & 22.83 & 0.33 & & & & 0.47 & 0.32 & 0.14 & -0.13 & 0.06 & 0.04 & 0.04 \\
\hline & RMR & 105 & 0.30 & 0.43 & 0.05 & 0.02 & $2.3 \times 10^{-3}$ & -0.04 & 0.05 & 0.51 & -0.02 & 0.01 & 0.13 & 0.10 \\
\hline & $\mathbf{M}_{\text {sum }}$ & 105 & 5.12 & 1.71 & 0.07 & 0.07 & 0.31 & 1.31 & 0.25 & $8.1 \times 10^{-7}$ & -0.10 & 0.05 & 0.07 & 0.23 \\
\hline & Endur. & 105 & 17.88 & 21.85 & 0.15 & 0.93 & 0.87 & -6.04 & 3.19 & 0.42 & 1.24 & 0.65 & 0.06 & 0.04 \\
\hline & Conduct. & 98 & 323.63 & 6.89 & & & & -0.50 & 6.89 & 0.94 & -1.07 & 1.35 & 0.43 & -0.01 \\
\hline & $\mathrm{M}_{\mathrm{b}}$ & 106 & 0.49 & 0.37 & & & & 0.45 & 0.37 & 0.22 & -0.08 & 0.07 & 0.28 & 0.01 \\
\hline \multirow[t]{2}{*}{$\triangleleft$} & RMR & 106 & 0.10 & 0.06 & 0.05 & 0.02 & $2.2 \times 10^{-3}$ & -0.02 & 0.06 & 0.71 & 0.00 & 0.00 & 0.82 & 0.06 \\
\hline & $\mathbf{M}_{\text {sum }}$ & 102 & 0.57 & 0.26 & -0.10 & 0.06 & 0.12 & 1.14 & 0.24 & $1.2 \times 10^{-5}$ & -0.09 & 0.05 & 0.06 & 0.19 \\
\hline
\end{tabular}

per second (Biomark HPR Plus Reader). We averaged the $\mathrm{T}_{\mathrm{b}}$ measurements over each one-minute interval of the trial and coded each one-minute interval as hypothermic or normothermic. We deemed birds hypothermic once they lost $10 \%$ of their initial $\mathrm{T}_{\mathrm{b}}$ and maintained $\mathrm{T}_{\mathrm{b}}$ below this level. Because birds differed in their initial $\mathrm{T}_{\mathrm{b}}\left(36-42^{\circ} \mathrm{C}\right)$, we repeated all analyses using the commonly accepted threshold of $37.0^{\circ} \mathrm{C}$ to define the hypothermic state, but this did not change our overall results (Tables S4-S5). In some cases, super glue did not hold the cloaca closed, and birds ejected their PIT tags during the trial. We removed from the sample 6 individuals for which PIT tag ejection occurred before hypothermia could be assessed. We also removed 8 individuals for which gaps longer than one minute existed (due to the position of the bird relative to the antenna) at critical periods that prevented precise detection of their hypothermic state, resulting in a total sample size of $n=92$. We used different respirometry chambers (either a custom-made plexiglass box or modified Nalgene) for the post-acclimation $\mathrm{M}_{\text {sum }}$ trials between years. Because these chambers had different thermal properties that may have contributed to differences in the way the individuals experienced temperature in the cold trials, we also tested for an effect of Year on risk of hypothermia (see below).

\section{Analyses}

We performed all analyses in $\mathrm{R}$. We first quantified the effects of acclimation temperature and duration on mass, tarsus length, and conductance using multiple regressions for pre-acclimation, post-acclimation, and $\Delta \mathrm{M}_{\mathrm{b}}$ values. We similarly used multiple regressions to quantify the effects of acclimation temperature and duration on $\mathrm{RMR}, \mathrm{M}_{\text {sum }}$, and endurance with $\mathrm{M}_{\mathrm{b}}$ as a covariate, as well as on $\Delta \mathrm{RMR}$ and $\Delta \mathrm{M}_{\text {sum }}$ with $\Delta \mathrm{M}_{\mathrm{b}}$ as a covariate. For all models, we also tested for an effect of a temperature $\times$ duration interaction but this term was generally not significant (Table S6). Additionally, we tested for associations among the phenotypic traits using Pearson correlation tests. We report means \pm standard deviations in the text.

To assess $\mathrm{T}_{\mathrm{b}}$ maintenance, we used $\mathrm{T}_{\mathrm{b}}$ interval data to fit Cox proportional hazards 
regression models using the survival package in $\mathrm{R}$ (Therneau, 2015). These standard time to event models analyse non-linear processes without assuming any one shape of response, allowing us to control for differences in temperature stimulus among individuals. We created survival objects with interval data and hypothermic status, then fit regressions using the function coxph to quantify the effects of cabinet temperature, temperature treatment, duration, and year with all terms clustered by individual on the risk of hypothermia. We first standardized all variables using the arm package (Gelman, 2008).

We used the same approach to assess the effect of phenotypic traits $\left(\mathrm{M}_{\mathrm{b}}\right.$, tarsus, $R M R, \mathrm{M}_{\text {sum }}$, endurance, and conductance) on the risk of hypothermia using a subset of individuals for which we had complete measurements $(n=84)$. Because of the large number of phenotypic variables potentially influencing $T_{b}$ maintenance, we used a model selection process whereby we tested all possible combinations (including two-way interactions) of the predictor variables. We evaluated all models using Akaike information criterion scores corrected for small sample sizes $\left(\mathrm{AIC}_{c}\right)$, where the model with the lowest $\mathrm{AIC}_{\mathrm{c}}$ score was considered the most well supported model. Because there was no single most well supported model (e.g., $w_{i}>0.90$; Grueber et al., 2011), we used model averaging to identify which predictor variables had significant effects on $\mathrm{T}_{\mathrm{b}}$ maintenance.

\section{RESULTS}

Prior to acclimation, treatment groups did not differ significantly in body size or metabolic traits (Table 1). Acclimation temperature and duration did not influence $\mathrm{M}_{\mathrm{b}}(\boldsymbol{\mu}=22.30 \pm 1.79 \mathrm{~g})$ or $\operatorname{RMR}\left(\boldsymbol{\mu}=1.38 \pm 0.29 \mathrm{ml} \mathrm{O}_{2} \bullet \mathrm{min}^{-1}\right.$; Table 1; Figure 1a). RMR was correlated with $\mathrm{M}_{\mathrm{b}}$ both before and after acclimation (Table 1$)$.

In contrast, cold-acclimated birds exhibited a $20 \%$ elevation in $\mathrm{M}_{\text {sum }}$ compared to Control birds (Table 1; Figure 1b). Duration of cold-exposure did not influence $\mathrm{M}_{\text {sum }}$ and $\mathrm{M}_{\text {sum }}$ was not correlated with $\mathrm{M}_{\mathrm{b}}$ before or after acclimation (Table 1). Similarly, $\mathrm{M}_{\text {sum }}$ did not correlate with RMR at either time point $\left(r_{\text {pre }}=-0.01, p_{\text {pre }}=0.85 ; r_{\text {post }}=0.15, p_{\text {post }}=0.13\right)$. Thermogenic endurance did not vary with temperature treatment or duration (Table 1), nor did it correlate with $\mathrm{M}_{\text {sum }}(r=-0.16, p=$ $0.11)$.

Table 2. Linear effects of Treatment, Duration (as categorical variable), and their interaction on conductance properties of the skin and plumage. Control Week 1 is reference.

\begin{tabular}{crcc}
\hline Variable & \multicolumn{1}{c}{$\beta$} & \multicolumn{1}{c}{$\mathrm{SE}$} & \multicolumn{1}{c}{$p$} \\
\hline Intercept & 316.88 & 10.06 & $<2.0 \times 10^{-16}$ \\
Treatment & 16.37 & 13.91 & 0.24 \\
Week 2 & -15.51 & 13.62 & 0.26 \\
Week 3 & 12.15 & 13.63 & 0.37 \\
Week 6 & 6.31 & 14.62 & 0.67 \\
Week 9 & 20.55 & 16.44 & 0.21 \\
Treatment $\times$ Week 2 & -4.38 & 19.23 & 0.82 \\
Treatment $\times$ Week 3 & -9.65 & 19.03 & 0.61 \\
Treatment $\times$ Week 6 & -28.78 & 20.18 & 0.16 \\
Treatment $\times$ Week 9 & $\mathbf{- 7 4 . 3 6}$ & $\mathbf{2 3 . 7 7}$ & $\mathbf{2 . 4 \times 1 0 ^ { - 3 }}$ \\
\hline
\end{tabular}


a.

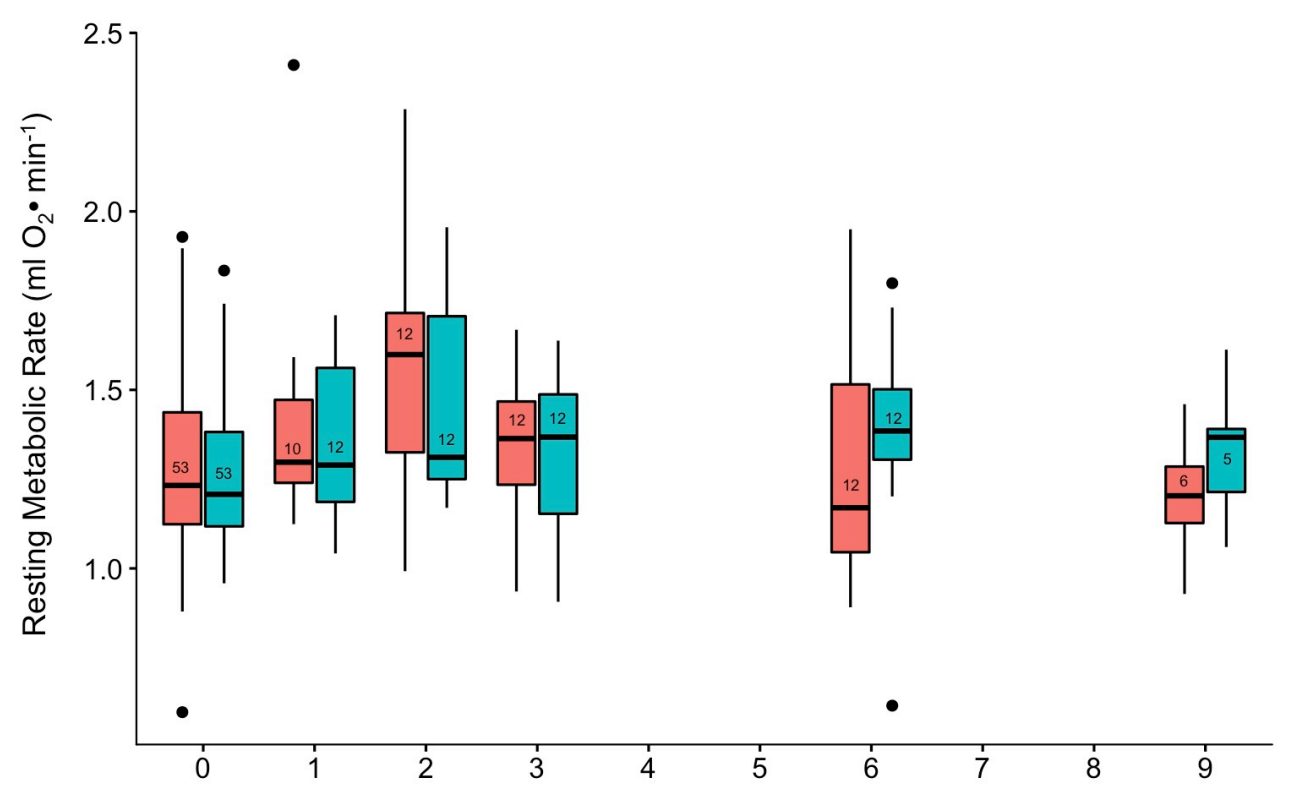

b.

Treatment Duration (in weeks)

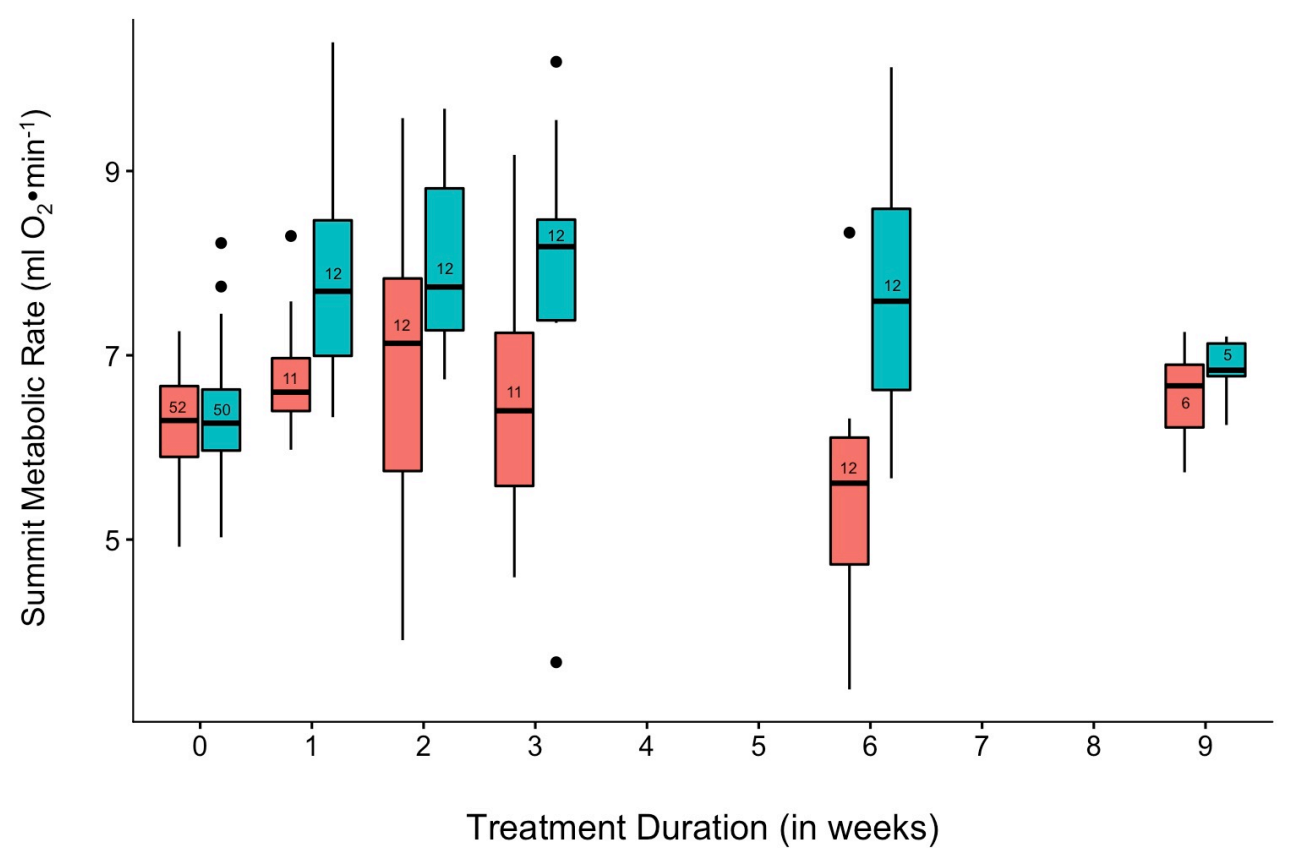

Figure 1. (a) Resting and (b) summit metabolic rate of juncos across treatments. Pre-acclimation measures for all individuals shown at Week 0 . Numbers in boxes indicate sample sizes for each group. Red $=$ Control; Blue $=$ Cold . Boxplots show the median values (horizontal line in the box), the 25th and 75th percentiles (lower and upper margins of the box) together with the minimum and maximum values $\leq 1.5 *$ IQR from the box margin (whiskers), and outlying points (circles). 


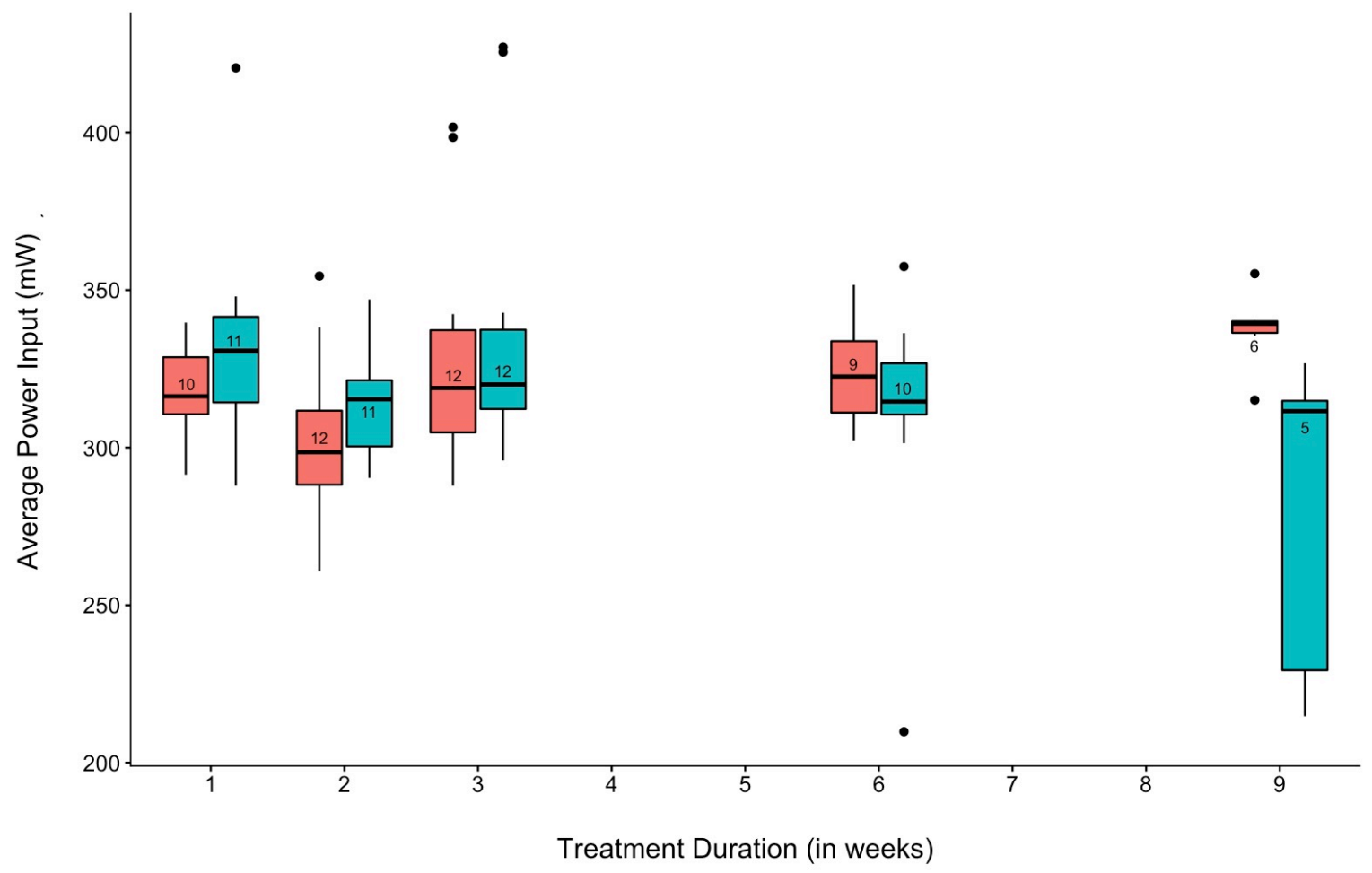

Figure 2. Heat loss properties of junco skins across treatment groups expressed as the power (mW) required to maintain core body temperature at $39^{\circ} \mathrm{C}$ with ambient temperature at $24^{\circ} \mathrm{C}$. Numbers in boxes indicate sample sizes for each group. Red $=$ Control; Blue $=$ Cold . For boxplot conventions, see legend to Fig. 1.

Conductance properties of the skin were largely unchanged across acclimation treatments (Table 1). However, there was an interaction between treatment and duration $(\beta=-8.52 \pm 2.56, p=$ 0.0013). To investigate this relationship, we reran our regression model with Duration as a categorical rather than continuous variable (Table 2). This revealed that the skin and plumage of Cold $W$ eek 9 birds exhibited a reduction in heat transfer compared to other groups (Figure 2). The average power input required to maintain core temperature at $39^{\circ} \mathrm{C}$ was not correlated with $\mathrm{M}_{\mathrm{b}}(r=-0.14, p$ $=0.16)$, tarsus length $(r=-0.11, p=0.29), \operatorname{RMR}(r=-0.14, p=0.16)$, or $\mathrm{M}_{\text {sum }}(r=0.03, p=0.77)$.

Temperature loss trajectories varied among individuals in acute cold trials. Some juncos showed a steady decline in $\mathrm{T}_{\mathrm{b}}$ over time, while others exhibited an oscillating $\mathrm{T}_{\mathrm{b}}$ (Figure 3 ). Thirteen individuals, distributed across treatment groups, demonstrated the ability to increase $\mathrm{T}_{\mathrm{b}}$ above normothermia after sustaining substantial losses in $\mathrm{T}_{\mathrm{b}}$. Birds did not differ in $\mathrm{T}_{\mathrm{b}}$ among temperature acclimation groups at the start of the trial ( $\mathrm{t}$-test: $\mathrm{t}(94)=0.45, p=0.65)$.

Higher cabinet temperatures elicited a reduced risk of hypothermia with a $17 \%$ reduction in per minute hazard for every $1^{\circ}$ increase in cabinet temperature (Table 3). For this reason, we included cabinet temperature as a covariate in all subsequent models. Cold-acclimated birds exhibited an $87 \%$ reduction in the per minute risk of hypothermia in acute cold trials (Figure 4a). Every week of acclimation duration was associated with a $15 \%$ reduction in the per minute risk of 
a.

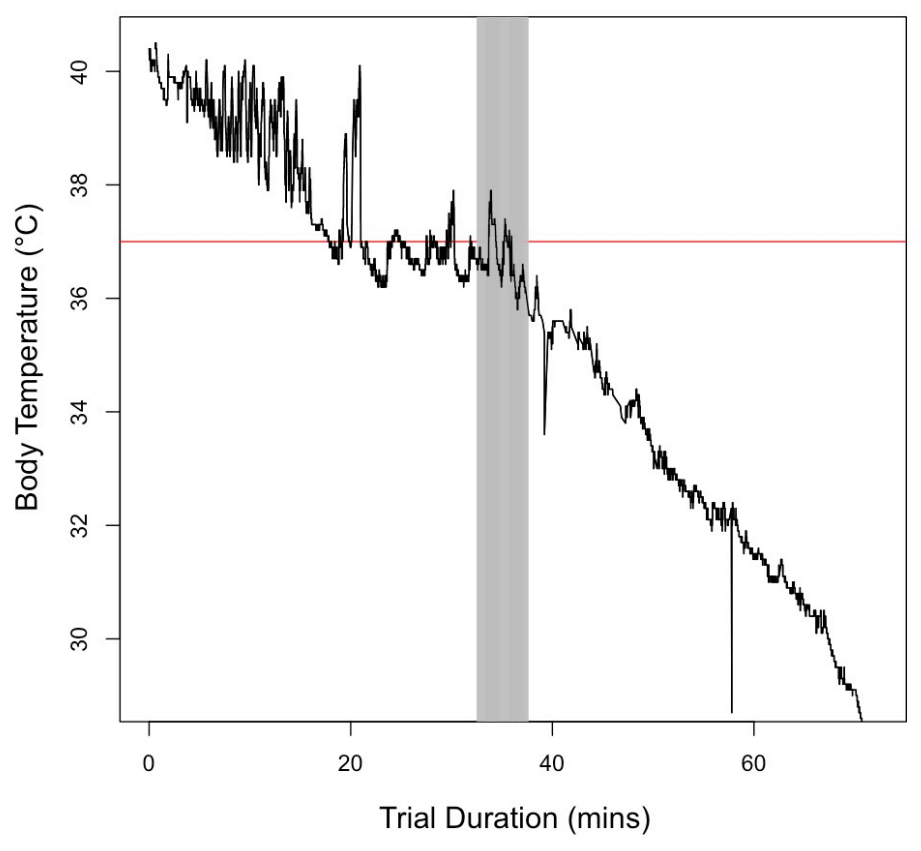

b.

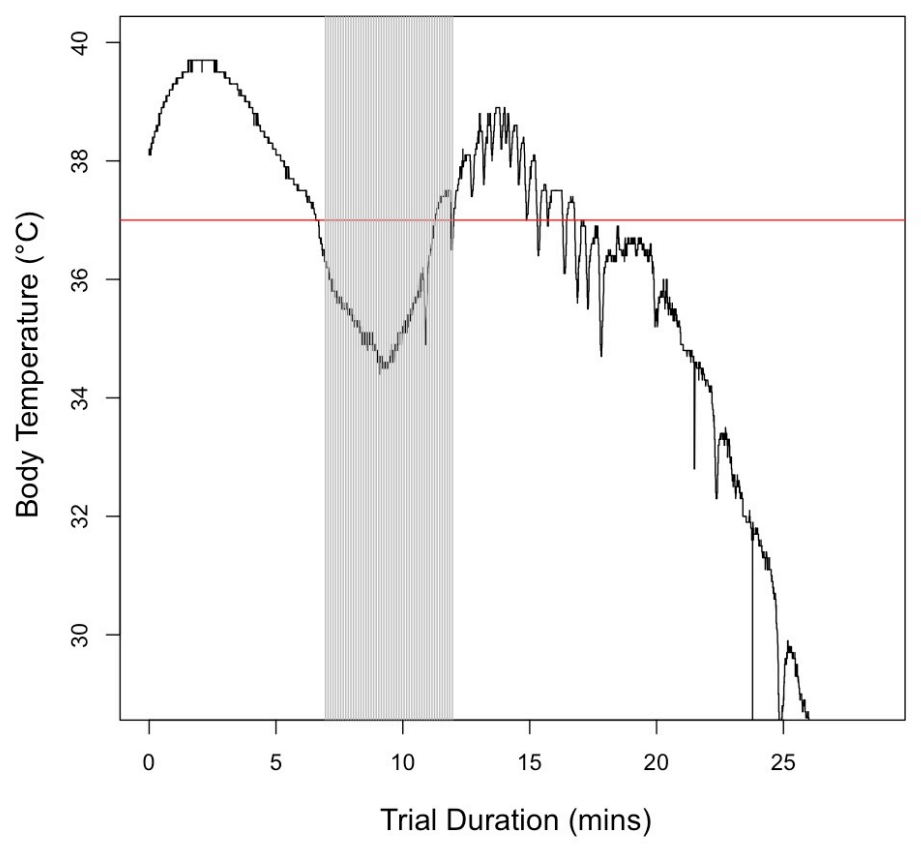

Figure 3. Example trajectories of body temperature loss during acute cold trials for an individual that exhibits (a) mostly continual loss and (b) one that regains normothermia. Black line = body temperature; red line $=37^{\circ} \mathrm{C}$; gray box is the 5 -minute period corresponding to $\mathrm{M}_{\text {sum. }}$. 
Table 3. Cox proportional hazards model output for $T_{b}$ maintenance as a function of cabinet temperature, acclimation temperature treatment, duration treatment, and year. Negative $\beta$ coefficients represent reduced risk of hypothermia. Hazards ratio (HR) is the exponent of the $\beta$ coefficient (i.e. a reduction in the hazard by this factor). Control treatment is reference for temperature effect. All continuous variables were standardized; bold indicates predictor variables with statistically significant effects on $\mathrm{T}_{\mathrm{b}}$ maintenance.

\begin{tabular}{cccccc}
\hline Variable & $\beta$ & SE & HR & $95 \%$ CI & $p$ \\
\hline Cabinet Temp. & $\mathbf{- 3 . 8 7}$ & $\mathbf{0 . 5 5}$ & $\mathbf{0 . 0 2}$ & $\mathbf{- 5 . 1 7 , - 2 . 5 8}$ & $4.8 \times \mathbf{1 0}^{-9}$ \\
Treatment & $\mathbf{- 2 . 0 6}$ & $\mathbf{0 . 4 8}$ & $\mathbf{0 . 1 3}$ & $\mathbf{- 3 . 2 2 , - 0 . 9 0}$ & $\mathbf{4 . 9 \times 1 0 ^ { - 4 }}$ \\
Period & $\mathbf{- 0 . 9 5}$ & $\mathbf{0 . 2 6}$ & $\mathbf{0 . 3 9}$ & $\mathbf{- 1 . 6 5 , - 0 . 2 6}$ & $\mathbf{7 . 4 \times 1 0 ^ { - 3 }}$ \\
Year & 0.53 & 0.25 & 1.70 & $-0.22,1.28$ & 0.17 \\
\hline
\end{tabular}

hypothermia. This was true for both the Cold and the Control treatments, so to further investigate this relationship, we tested for the effect of duration as a categorical, rather than continuous variable. Within the Control treatment, only Week 9 individuals showed a reduction in hypothermia risk compared to Week 1 birds (Table 4a). However, within the cold-acclimated birds, Weeks 2, 6, and 9 all showed a reduced risk of hypothermia compared to Week 1 (Table 4b; Figure 4b). Year did not influence the risk of hypothermia (Table 3).

There was no single model best predicting risk of hypothermia using phenotypic traits (Table 5). However, model averaging identified $\mathrm{M}_{\text {sum }}$, Endurance, and the interaction between $\mathrm{M}_{\text {sum }} \times$ Endurance as significant predictor variables (Table 6). The interaction term indicates that birds with both higher $\mathrm{M}_{\text {sum }}$ and Endurance were better able to maintain their $\mathrm{T}_{\mathrm{b}}$. In comparison, $\mathrm{M}_{\mathrm{b}}$, tarsus length, RMR, and conductance were not correlated with time to hypothermia (Table 6).

Table 4. Survival model output for hypothermic state as a function of treatment group for (a) Control birds only and (b) Cold birds only. Week 1 as reference. Negative $\beta$ coefficients represent reduced risk of hypothermia. Hazards ratio (HR) is the exponent of the $\beta$ coefficient (i.e. a reduction in the hazard by this factor). Bold indicates predictor variables with statistically significant effects on $\mathrm{T}_{\mathrm{b}}$ maintenance.

(a)

\begin{tabular}{ccccc}
\hline Variable & $\beta$ & SE & HR & $p$ \\
\hline Cabinet Temp. & $\mathbf{- 0 . 1 5}$ & $\mathbf{0 . 0 6}$ & $\mathbf{0 . 8 6}$ & $\mathbf{0 . 0 5}$ \\
Week 2 & -0.98 & 0.51 & 0.38 & 0.36 \\
Week 3 & -1.27 & 0.50 & 0.28 & 0.14 \\
Week 6 & 0.14 & 0.50 & 1.15 & 0.84 \\
Week 9 & $\mathbf{- 2 . 2 3}$ & $\mathbf{0 . 5 9}$ & $\mathbf{0 . 1 1}$ & $\mathbf{1 . 8 \times 1 0 ^ { - 4 }}$ \\
\hline
\end{tabular}

(b)

\begin{tabular}{ccccc}
\hline Variable & $\beta$ & SE & HR & $p$ \\
\hline Cabinet Temp. & $\mathbf{- 0 . 5 0}$ & $\mathbf{0 . 0 8}$ & $\mathbf{0 . 6 1}$ & $\mathbf{2 . 5 \times 1 0 ^ { - 7 }}$ \\
Week 2 & $\mathbf{- 1 . 8 2}$ & $\mathbf{0 . 5 2}$ & $\mathbf{0 . 1 6}$ & $\mathbf{1 . 1 \times 1 0 ^ { - 3 }}$ \\
Week 3 & -1.01 & 0.51 & 0.36 & 0.11 \\
Week 6 & $\mathbf{- 1 . 2 3}$ & $\mathbf{0 . 4 9}$ & $\mathbf{0 . 2 9}$ & $\mathbf{0 . 0 1}$ \\
Week 9 & $\mathbf{- 4 . 4 4}$ & $\mathbf{0 . 8 4}$ & $\mathbf{0 . 0 1}$ & $\mathbf{6 . 1 \times 1 0 ^ { - 4 }}$ \\
\hline
\end{tabular}


a.

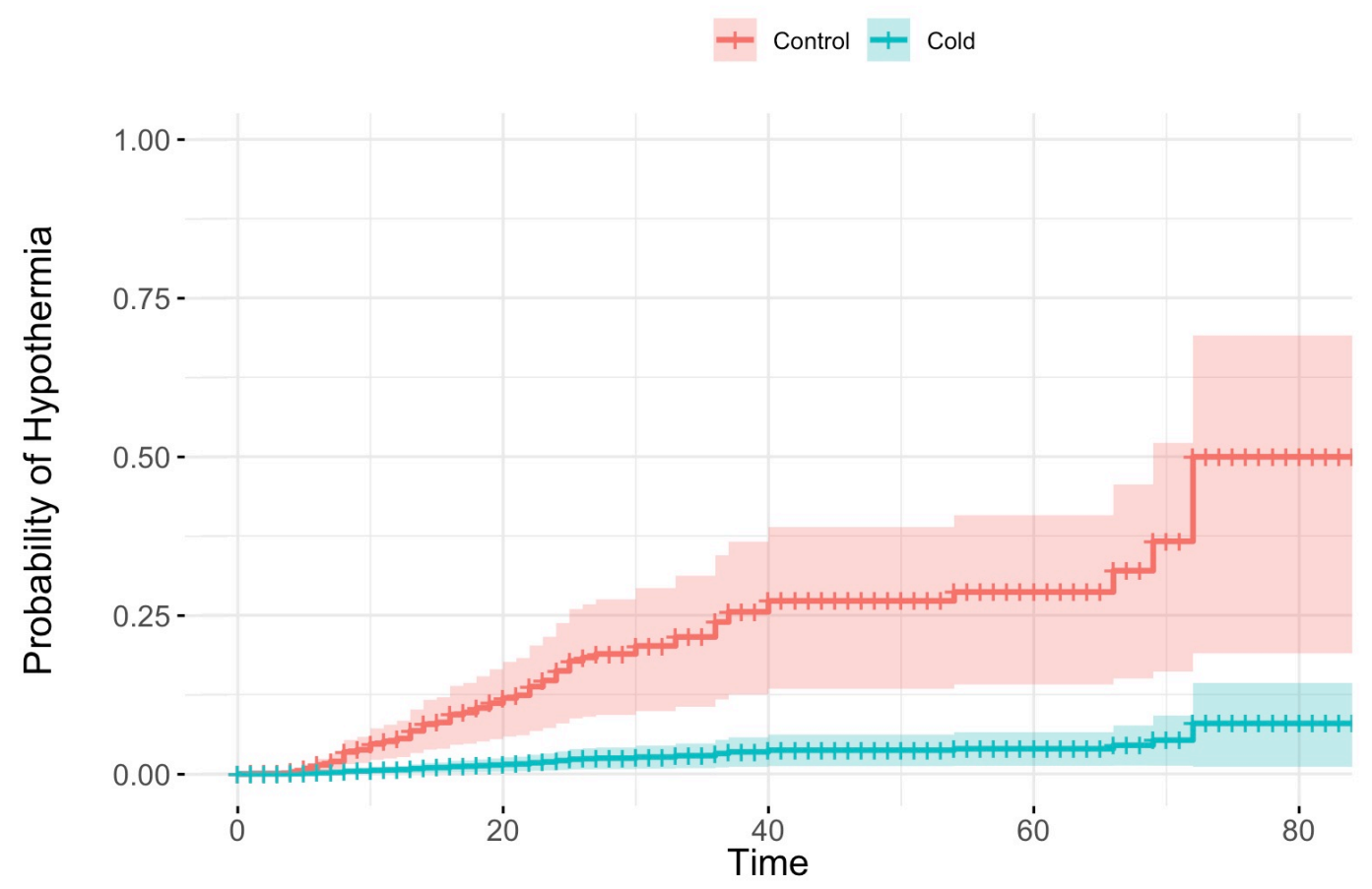

b.
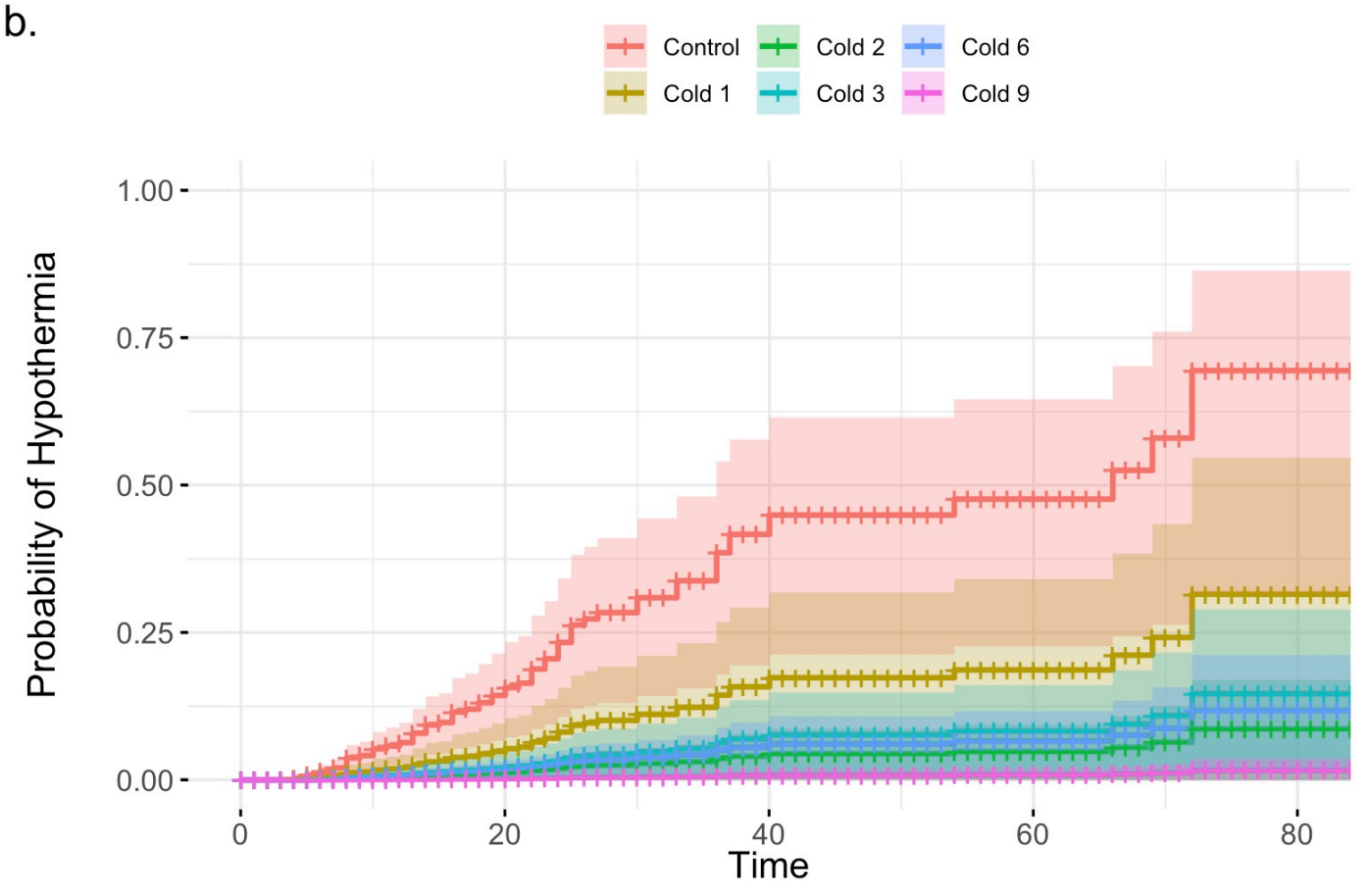

Figure 4. Survival curves depicting time to hypothermia in acute cold trials across (a) temperature $(n=92)$ and (b) duration treatments $(n=86)$ while controlling for cabinet temperature. Control treatments (excluding Week 9) combined in (b). Regression lines shown with shaded areas representing $95 \%$ confidence intervals. 
Table 5. Highest-ranked models (with lowest $\mathrm{AIC}_{\mathrm{c}}$ scores) in candidate set for effects of phenotypic variables on the maintenance of $\mathrm{T}_{\mathrm{b}}$ using Cox proportional hazards models. Only models with $\Delta \mathrm{AIC}_{\mathrm{c}}<4$ are reported. $K$ indicates the number of parameters in each model; Cabinet refers to the cabinet temperature during the cold trial.

\begin{tabular}{|c|c|c|c|c|}
\hline Candidate Model & K & $\mathrm{AIC}_{\mathrm{c}}$ & $\Delta \mathrm{AIC}_{\mathrm{c}}$ & $w_{i}$ \\
\hline Cabinet + Endurance $\times \mathbf{M}_{\text {sum }}+\mathbf{R M R}$ & 5 & 1007.9 & 0.0 & 0.23 \\
\hline Cabinet + Conductance + Endurance $\times \mathbf{M}_{\text {sum }}+\mathbf{R M R}$ & 6 & 1009.2 & 1.3 & 0.12 \\
\hline Cabinet + Endurance $\times \mathbf{M}_{\text {sum }}+\mathbf{R M R}+$ Tarsus & 6 & 1009.6 & 1.7 & 0.10 \\
\hline Cabinet + Endurance $\times \mathbf{M}_{\text {sum }}+\mathbf{M}_{\mathrm{b}}+\mathbf{R M R}$ & 6 & 1009.6 & 1.7 & 0.10 \\
\hline Cabinet + Conductance + Endurance $\times M_{\text {sum }}+M_{b}+R M R$ & 7 & 1010.9 & 3.0 & 0.05 \\
\hline Cabinet + Endurance $\times \mathbf{M}_{\text {sum }}+\mathbf{M}_{\mathrm{b}}+\mathbf{R M R}+$ Tarsus & 7 & 1010.9 & 3.0 & 0.05 \\
\hline Cabinet + Conductance + Endurance $\times \mathbf{M}_{\text {sum }}+\mathbf{R M R}+$ Tarsus & 7 & 1011.0 & 3.1 & 0.05 \\
\hline Cabinet + Endurance $\times \mathbf{M}_{\text {sum }}$ & 4 & 1011.2 & 3.3 & 0.04 \\
\hline Cabinet + Conductance + Endurance $\times \mathbf{M}_{\text {sum }}$ & 5 & 1011.3 & 3.4 & 0.04 \\
\hline
\end{tabular}

\section{DISCUSSION}

To support their energetic lifestyle, homeothermic endotherms maintain a relatively high and constant $\mathrm{T}_{\mathrm{b}}$ despite changes in the environment. Regulating $\mathrm{T}_{\mathrm{b}}$ within this narrow window necessitates responding to changes in their environment that may arise both predictably and stochastically. Here we show that the capacity for $T_{b}$ maintenance is a flexible avian phenotype that can acclimate to changes in the thermal environment. The ability to maintain normothermia during acute cold exposure improved with cold acclimation, as well as the duration of the acclimation treatment. Modifications to thermoregulatory ability occurred on relatively short time scales (within one week) and without changes in photoperiod, suggesting that juncos can match their thermoregulatory physiology to current thermal conditions independent of broad-scale seasonal cues. At the same time, further enhancements to the ability to maintain $\mathrm{T}_{\mathrm{b}}$ were made over successive time steps, indicating a lag in the induction of some physiological modifications. These results emphasize the potential for temporal constraints on individual flexibility.

\section{Correlates of improved $\mathbf{T}_{\mathrm{b}}$ maintenance ability}

Summit metabolic rate has previously been implicated as the main factor governing avian cold tolerance in studies of seasonal flexibility (Swanson, 2010). We found that $\mathrm{M}_{\text {sum }}$ increased with cold acclimation within one week of cold exposure, but that further enhancements to this trait did not occur with longer acclimation durations. In this respect, our study is unique in that it shows responses in $\mathrm{M}_{\text {sum }}$ occurring on the order of days rather than weeks or months. Furthermore, our results indicate that the magnitude of the change in $\mathrm{M}_{\text {sum }}$ over this short timescale is on the order of seasonal increases in $\mathrm{M}_{\text {sum }}$ exhibited in wild juncos between summer and winter $(28 \%$, Swanson, 1990a), as well as that previously shown for juncos exposed to laboratory acclimations under more moderate conditions $\left(16-19 \%\right.$ at $3^{\circ} \mathrm{C}$ for six weeks, Swanson et al., 2014). The comparable magnitude of response to these two different temperature treatments contrasts with previous work showing that wild juncos and other birds modulate $\mathrm{M}_{\text {sum }}$ with environmental temperature across the winter (Swanson \& Olmstead, 1999). Taken together, these findings suggest that $\mathbf{M}_{\text {sum }}$ might be coarsely adjusted, rather than fine-tuned, to environmental temperature, and that there may be limits to their flexibility in response to temperature variation (Petit and Vézina, 2014). Dissecting the relative contribution of subordinate phenotypic traits to $\mathrm{M}_{\text {sum }}-$ e.g., pectoralis muscle size, hematocrit, or cellular metabolic intensity (Liknes \& Swanson, 2011; Swanson, 1990b; Swanson et 
al., 2014) — will illustrate how birds build this phenotype and which traits (if any) may be limiting its flexibility.

Individuals characterized by both elevated $\mathrm{M}_{\text {sum }}$ and the ability to sustain heightened $\mathrm{M}_{\text {sum }}$ (endurance) were also capable of maintaining normothermia longer, indicating an additive effect of enhancing these two phenotypes. Nonetheless, we saw no effect of acclimation treatment or duration on endurance and individuals continued to enhance their ability to maintain normothermia in successive weeks long after $\mathrm{M}_{\text {sum }}$ plateaued. These results suggest that either these indices are insufficient indicators of total thermogenic capacity or that individuals reduced their thermal conductance at these later time points.

In support of this latter possibility, we found that conductance of the skin and plumage decreased in response to our temperature stimulus. This finding prompts questions about the exact mechanism underlying such a modification. Although we cannot distinguish between potential adjustments made to the properties of the skin or the plumage, the fact that heat loss was only reduced at the last sampling point (Week 9) suggests that alterations to thermal conductance may require significant time to implement. We did not see evidence that birds were molting large amount of feathers during the acclimation, as was obvious when birds first entered captivity (Stager pers. obs.). Moreover, avian molt is closely tied to photoperiod (Danner et al., 2015), yet conductance changed in the absence of variation in photoperiod. Instead, it seems plausible that birds may have added body feathers to their existing plumage. Previous work has shown that juncos increase plumage mass in winter compared to summer (Swanson, 1991), as do American Goldfinches (Carduelis tristis), which additionally have been shown to possess a greater percentage of plumulaceous barbules, as well as more barbules per barb, in winter than summer (Middleton, 1986). However, goldfinches undergo an alternate molt in the spring, in addition to the basic molt in autumn, whereas juncos exhibit just the single autumn molt (Pyle, 1997). Thus if juncos did selectively add feathers to reduce conductance in the cold, it would suggest that they concomitantly lose select feathers before the subsequent summer to enable increased heat loss when they need it most. Alternatively, it is possible that changes were made to the heat transfer properties of the skin itself. For example, avian skin composition can be flexibly remodeled on the time scales of our experiments in response to humidity (Muñoz-Garcia et al., 2008). It should be noted that while the Week 9 treatment was our smallest sample size, our results are statistically robust. Future studies would therefore profitably

Table 6. Model-averaged coefficients for phenotypic variables affecting the maintenance of $\mathrm{T}_{\mathrm{b}}$ assessed using Cox proportional hazards models. Negative $\beta$ coefficients represent reduced risk of hypothermia. Hazards ratio (HR) is the exponent of the $\beta$ coefficient (i.e. a reduction in the hazard by this factor). All continuous variables were standardized; bold indicates predictor variables with statistically significant effects on $\mathrm{T}_{\mathrm{b}}$ maintenance.

\begin{tabular}{lccccc}
\hline Variable & $\beta$ & $\mathrm{SE}$ & $\mathrm{HR}$ & $95 \%$ CI & $p$ \\
\hline Cabinet Temp. & -0.93 & 0.49 & 0.39 & $-1.90,0.02$ & 0.06 \\
Endurance & $\mathbf{- 2 . 0 2}$ & $\mathbf{0 . 6 1}$ & $\mathbf{0 . 1 3}$ & $\mathbf{- 3 . 2 2 , - 0 . 8 1}$ & $\mathbf{0 . 0 0 1}$ \\
$\mathrm{RMR}$ & 0.47 & 0.41 & 1.60 & $-0.26,1.31$ & 0.26 \\
$\mathbf{M}_{\text {sum }}$ & $\mathbf{- 1 . 0 4}$ & $\mathbf{0 . 4 5}$ & $\mathbf{0 . 3 5}$ & $\mathbf{- 1 . 9 3 , - 0 . 1 5}$ & $\mathbf{0 . 0 2}$ \\
Endurance $\times \mathbf{M}_{\text {sum }}$ & $\mathbf{- 2 . 1 4}$ & $\mathbf{0 . 9 5}$ & $\mathbf{0 . 1 2}$ & $\mathbf{- 4 . 0 0 , - 0 . 2 9}$ & $\mathbf{0 . 0 2}$ \\
Conductance & 0.09 & 0.24 & 1.09 & $-0.41,0.98$ & 0.70 \\
Tarsus & -0.06 & 0.19 & 1.06 & $-0.85,0.37$ & 0.75 \\
$\mathrm{M}_{\mathrm{b}}$ & 0.06 & 0.23 & 1.06 & $-0.57,1.02$ & 0.80 \\
\hline
\end{tabular}


combine our methodology here with data on the time course of plumage quality and mass to further elucidate the role that heat saving mechanisms might play in avian $\mathrm{T}_{\mathrm{b}}$ maintenance.

While reduced thermal conductance may explain the final boost in ability to maintain normothermia seen at $W$ eek 9 , variation in neither $\mathrm{M}_{\text {sum }}$ or conductance explain the increase in $\mathrm{T}_{\mathrm{b}}$ maintenance at Weeks 2 and 6. One potential reason for this disparity is that we were unable to quantify total heat loss in live birds and thus may have overlooked additional factors that contribute to minimum conductance - like vasoconstriction (Irving and Krog, 1955), posture (Pavlovic et al., 2019), and ptiloerection (Hohtola, Rintamäki, \& Hissa, 1980) - that may have varied across treatments. To this point, we can anecdotally report from observations made during cold exposure trials that juncos sat on their feet, puffed up their feathers, but did not tuck their heads under their wings; however, we did not quantify these postures. A second potential explanation is that assaying total oxygen consumption could mask potential changes to thermogenic efficiency. For example, juncos may achieve higher metabolic efficiency by increasing fiber size within their muscle, thereby allowing for greater contraction force while simultaneously reducing basal metabolic cost because larger muscle fibers require less energy by $\mathrm{Na}^{+} / \mathrm{K}^{+}$ATPase to maintain sarcolemmal membrane potential (Jimenez et al., 2013). Such changes have been documented in Black-capped chickadees (Poecile atricapillus), which exhibit seasonal decreases in muscle fiber diameter from spring to summer (Jimenez et al., 2019), as well as increases with cold acclimation (Vezina et al., 2020). Additionally, if adult birds are employing non-shivering thermogenesis, the relative proportion of shivering to nonshivering processes could be altered seasonally. Direct measures of shivering and/or non-shivering thermogenesis, however, are needed to test for these potential changes. Our results thus point to exciting directions for further exploration regarding the mechanisms governing seasonal acclimatization in avian $\mathrm{T}_{\mathrm{b}}$ maintenance.

\section{Thermoregulation and broad-scale ecogeographic patterns}

Spatial variation in basal metabolic rate (BMR) is often interpreted as a thermal adaptation to cold conditions, whereby colder climates are correlated with higher endothermic BMR (Lovegrove, 2003; Wiersma et al., 2007). Changes in BMR have also been implicated as a mechanism and/or byproduct of avian thermal acclimation across seasons (Dutenhoffer and Swanson, 1996). Here we did not find increases in RMR associated with cold acclimation. We quantified RMR rather than BMR, meaning that birds were not fasted before measurements. Nonetheless, RMR post-acclimation was similar to previously published BMR values for wild juncos (Swanson et al., 2012). We found that RMR was not correlated with other performance phenotypes $\left(M_{\text {sum }}\right.$, conductance, or $T_{b}$ maintenance), implying that it is not a good indicator of avian cold tolerance. This result also agrees with previous work showing that $\mathrm{M}_{\text {sum }}$ and RMR can be uncoupled (Petit et al., 2013; Swanson et al., 2012). Finally, it indicates that the energetic costs associated with enhancing thermoregulatory ability - like building the metabolic machinery associated with increased $\mathrm{M}_{\text {sum }}$ - do not necessarily manifest as higher resting energetic use.

$\mathrm{M}_{\text {sum }}$ is commonly used as a proxy for cold tolerance in macrophysiological studies (e.g., Stager et al., 2016). However, our results highlight a disconnect between these two measures. Although junco $\mathrm{M}_{\text {sum }}$ was correlated with $\mathrm{T}_{\mathrm{b}}$ maintenance in the cold, it was not as strong a predictor of $T_{b}$ maintenance as was endurance, and it was the interaction between $M_{\text {sum }}$ and endurance that had the largest effect on $\mathrm{T}_{\mathrm{b}}$ maintenance. Furthermore, the amount of variation in $\mathrm{T}_{\mathrm{b}}$ maintenance explained by $\mathrm{M}_{\text {sum }}$ alone was relatively small. These results echo those of a previous study in which variation in $\mathrm{M}_{\text {sum }}$ did not match variation in cold tolerance in two other, disparate, junco populations (Swanson, 1993). $\mathrm{M}_{\text {sum }}$ may, therefore, not be as strong a proxy of cold tolerance as frequently thought. Nonetheless, to discern whether this pattern can be generalized to other taxa, we encourage 
the collection of $\mathrm{T}_{\mathrm{b}}$ data to assess normothermic ability as we have done here. Such data is increasingly easy to obtain using PIT tags and other next-generation tracking technologies (e.g., Parr et al., 2019)

\section{Responding to fluctuating environmental conditions}

Nicknamed "snowbirds" for their winter tenacity, juncos are not unique in their cold hardiness. Their close relative, the White-throated Sparrow (Zonotrichia albicolli), has been acclimated to even colder conditions than those employed here $\left(3 \mathrm{wk}\right.$ at $-20^{\circ} \mathrm{C}$ ) (McWilliams and Karasov, 2014), and other small songbirds have survived short periods in the lab at $-60^{\circ} \mathrm{C}$ (Dawson and Carey, 1976). Given that the climatic conditions juncos experience vary across their broad geographic distribution, junco populations may also differ in their thermoregulatory abilities and the underlying physiological responses they use to moderate $T_{b}$. Acclimatizing to these cold temperatures in the wild likely comes with tradeoffs, such as increased exposure to predators as a consequence of increased time spent foraging (Lima, 1985). Moreover, as our results demonstrate, the duration of the cold period may dictate which physiological strategies are utilized. For instance, we found that juncos are capable of responding to thermal cues with large changes in $\mathrm{M}_{\text {sum }}$ occurring within one week. However, rapid changes likely require energetic input to fuel this physiological remodeling, in addition to those required to elevate aerobically powered shivering thermogenesis.

Another short-term strategy that birds use to cope with cold temperatures is facultative heterothermia (Mckechnie and Lovegrove, 2002). We witnessed similar patterns of oscillating $T_{b}$ in some juncos, whereby they raised $\mathrm{T}_{\mathrm{b}}$ to normothermic levels following a period of hypothermia. Counter to previous findings (Swanson, 1991), this suggests that juncos may employ facultative heterothermia as an energy saving mechanism. However, we did not find evidence for acclimation in this strategy — as members of both temperature treatments exhibited heterothermia — nor that birds differed in their starting $\mathrm{T}_{\mathrm{b}}$ among temperature treatments. The White-crowned Sparrow $(Z$. leucophrys), another close relative of the junco, has been shown to lower their $\mathrm{T}_{\mathrm{b}}$ by $3.6^{\circ} \mathrm{C}$ (Ketterson and King, 1977), but we found that juncos could lower their $\mathrm{T}_{\mathrm{b}}$ by as much as $7^{\circ} \mathrm{C}$ and still recover normothermia during an acute cold trial. Although we did not assess potential consequences of hypothermia in this context, $7^{\circ} \mathrm{C}$ is well within the range of $\mathrm{T}_{\mathrm{b}}$ reductions observed in other passerines (Mckechnie and Lovegrove, 2002). Furthermore, a nightly reduction in $\mathrm{T}_{\mathrm{b}}$ of this magnitude is estimated to reduce the energy expenditure of Parus tits by up to $30 \%$ and increase their over-wintering survival by 58\% (Brodin et al., 2017). Like other birds, however, juncos suffer impaired mobility at such low $\mathrm{T}_{\mathrm{b}}$ (Stager pers. obs.). While rest-phase hypothermia may be especially useful at night when activity levels are reduced, it alone may not be a good strategy to cope with cold temperatures during the day when birds need to eat, move, and avoid predators (Brodin et al., 2017).

Juncos may thus be layering longer-term modifications - like the observed changes in conductance - on top of these shorter-term mechanisms to arrive at the optimal phenotype for the challenge at hand. If widespread, this would provide birds with a host of strategies to employ, each of which may be useful over different time scales. As a result, in the face of increasing climatic variability, some birds may be well equipped to deal with potential mismatches between photoperiod and temperature that lead to thermoregulatory challenges in the cold. However, their ability to employ these different strategies is likely dependent on their access to sufficient food to fuel and maintain these phenotypic changes. Because food resources are also likely to vary in response to global change (Rafferty, 2017; Williams and Jackson, 2007), future work should investigate the complex interactions between environmental change, subsequent physiological responses, and their energetic costs. 


\section{ACKNOWLEDGEMENTS}

We are especially thankful to Phred Benham, Ryan Mahar, Nick Sly, Hannah Specht, and Stan Senner for their assistance in catching birds. We also thank Frank Moss for logistical assistance, Hailey Bunker for help with husbandry, and Keely Corder, Rena Schweizer, Jon Velotta, and Cole Wolf for comments on an earlier version of this manuscript.

\section{COMPETING INTERESTS}

The authors declare no competing or financial interests.

\section{AUTHORS' CONTRIBUTIONS}

MS and ZAC conceived of the study; NRS helped capture birds; BW'T designed the conductance trials; MS performed all data collection and analyses, and drafted the manuscript; NRS, BWT, and ZAC contributed edits to the manuscript. All authors gave final approval for publication.

\section{FUNDING}

This work was supported by the National Science Foundation [GRFP to MS, IOS-1656120 to BWT] and the University of Montana [startup to ZAC].

\section{DATA AVAILABILITY}

All data are available in the electronic supplementary material.

\section{ETHICS}

All procedures were approved by the University of Montana Animal Care Committee (Protocol 01016ZCDBS-020916). Birds were collected with permission from Montana Fish Wildlife \& Parks (permits 2016-013 and 2017-067-W, issued to MS) and the US Fish \& Wildlife Service (permit MB84376B-1 to MS).

\section{REFERENCES}

Bennett, A. and Ruben, J. (1979). Endothermy and activity in vertebrates. Science 206, 649-654.

Brodin, A., Nilsson, J.-Å. and Nord, A. (2017). Adaptive temperature regulation in the little bird in winter: predictions from a stochastic dynamic programming model. Oecologia 185, 43-54.

Buckley, L. B., Khaliq, I., Swanson, D. L. and Hof, C. (2018). Does metabolism constrain bird and mammal ranges and predict shifts in response to climate change? Ecol Evol ece3.4537.

Cheviron, Z. A., Bachman, G. C. and Storz, J. F. (2013). Contributions of phenotypic plasticity to differences in thermogenic performance between highland and lowland deer mice. Journal of Experimental Biology 216, 1160-1166.

Crompton, A. W., Taylor, C. R. and Jagger, J. A. (1978). Evolution of homeothermy in mammals. Nature 272, 333-336. 
Danner, R. M., Greenberg, R. S., Danner, J. E. and Walters, J. R. (2015). Winter food limits timing of pre-alternate moult in a short-distance migratory bird. FunctZEcol 29, 259-267.

Dawson, W. R. and Carey, C. (1976). Seasonal acclimatization to temperature in Cardueline Finches. Journal of Comparative Physiology A: Sensory, Neural, and Behavioral Physiology 112, 317333.

Dawson, W. R. and O'Connor, T. P. (1996). Energetic features of avian thermoregulatory responses. In Avian Energetics and Nutritional Ecology (ed. Carey, C.), pp. 85-124. Boston, MA: Springer US.

Dawson, W. R. and Smith, B. K. (1986). Metabolic acclimatization in the American Goldfinch (Carduelis tristis). In Living in the Cold: physiological and biochemical adaptations (ed. Heller, H. C.), pp. 427-434. Amsterdam: Elsevier.

Douglas, T. K., Cooper, C. E. and Withers, P. C. (2017). Avian torpor or alternative thermoregulatory strategies for overwintering? J Exp Biol 220, 1341-1349.

Dutenhoffer, M. S. and Swanson, D. L. (1996). Relationship of basal to summit metabolic rate in passerine birds and the aerobic capacity model for the evolution of endothermy. Physiological Zoology 69, 1232-1254.

Ferretti, A., Rattenborg, N. C., Ruf, T., McWilliams, S. R., Cardinale, M. and Fusani, L. (2019). Sleeping unsafely tucked in to conserve energy in a nocturnal migratory songbird. Current Biology 29, 2766-2772.e4.

Gelman, A. (2008). Scaling regression inputs by dividing by two standard deviations. Statist. Med. 27, 2865-2873.

Grueber, C. E., Nakagawa, S., Laws, R. J. and Jamieson, I. G. (2011). Multimodel inference in ecology and evolution: challenges and solutions: Multimodel inference. Journal of Evolutionary Biology 24, 699-711.

Hohtola, E. (2002). Facultative and obligatory thermogenesis in young birds: a cautionary note. Comparative Biochemistry and Physiology Part A: Molecular \& Integrative Physiology 131, 733-739.

Hohtola, E., Rintamäki, H. and Hissa, R. (1980). Shivering and ptiloerection as complementary cold defense responses in the pigeon during sleep and wakefulness. J Comp Physiol B 136, 7781.

Irving, L. and Krog, J. (1955). Temperature of skin in the Arctic as a regulator of heat. Journal of Applied Physiology 7, 355-364.

Jimenez, A. G., Dillaman, R. M. and Kinsey, S. T. (2013). Large fibre size in skeletal muscle is metabolically advantageous. Nat Commun 4, 2150.

Jimenez, A. G., O’Connor, E. S., Brown, K. J. and Briggs, C. W. (2019). Seasonal muscle ultrastructure plasticity and resistance of muscle structural changes during temperature increases in resident black-capped chickadees and rock pigeons. J Exp Biol 222, jeb201855. 
Ketterson, E. D. and King, J. R. (1977). Metabolic and behavioral responses to fasting in the White-crowned Sparrow (Zonotrichia leucophrys gambelii). Physiological Zoology 50, 115-129.

Kolstad, E. W., Breiteig, T. and Scaife, A. A. (2010). The association between stratospheric weak polar vortex events and cold air outbreaks in the Northern Hemisphere. Q.J.R. Meteorol. Soc. 136, 886-893.

Korhonen, K. (1981). Temperature in the nocturnal shelters of the redpoll (Acanthis flammea L.) and the Siberian tit (Parus cinctus Budd.) in winter. Annales Zoologici Fennici 18, 165-167.

Lighton, J. (2008). Measuring metabolic rates: a manual for scientists. New York: Oxford University Press.

Liknes, E. T. and Swanson, D. L. (2011). Phenotypic flexibility of body composition associated with seasonal acclimatization in passerine birds. Journal of Thermal Biology 36, 363-370.

Lima, S. L. (1985). Maximizing feeding efficiency and minimizing time exposed to predators: a trade-off in the black-capped chickadee. Oecologia 66, 60-67.

Londoño, G. A., Chappell, M. A., Jankowski, J. E. and Robinson, S. K. (2017). Do thermoregulatory costs limit altitude distributions of Andean forest birds? Funct Ecol 31, 204 215.

Lovegrove, B. G. (2003). The influence of climate on the basal metabolic rate of small mammals: a slow-fast metabolic continuum. J Comp Physiol B 173, 87-112.

Marsh, R. L. and Dawson, W. R. (1989). Avian Adjustments to Cold. In Animal Adaptation to Cold (ed. Wang, L. C. H.), pp. 205-253. Berlin, Heidelberg: Springer.

Mckechnie, A. E. and Lovegrove, B. G. (2002). Avian facultative hypothermic responses: a review. The Condor 104, 705-724.

McWilliams, S. R. and Karasov, W. H. (2014). Spare capacity and phenotypic flexibility in the digestive system of a migratory bird: defining the limits of animal design. Proc. R. Soc. B 281, 20140308.

Middleton, A. L. A. (1986). Seasonal changes in plumage structure and body composition of the American Goldfinch, Carduelis tristis. Canadian Field Naturalist 100, 545-549.

Møller, A. P. (2015). The allometry of number of feathers in birds changes seasonally. Avian Res 6, 2.

Morris, D. (1956). The feather postures of birds and the problem of the origin of social signals. Behaviour 9, 75-113.

Muñoz-Garcia, A., Cox, R. M. and Williams, J. B. (2008). Phenotypic flexibility in cutaneous water loss and lipids of the stratum corneum in House Sparrows (Passer domesticus) following acclimation to high and low humidity. Physiological and Biochemical Zoology 81, 87-96. 
Nolan, Jr., V., Ketterson, E. D., Cristol, D. A., Rogers, C. M., Clotfelter, E. D., Titus, R. C., Schoech, S. J. and Snajdr, E. (2002). Dark-eyed Junco (Junco hyemalis). Birds N. Am.

O’Connor, T. P. (1995). Metabolic characteristics and body composition in house finches: effects of seasonal acclimatization. J Comp Physiol B 165, 298-305.

Osváth, G., Daubner, T., Dyke, G., Fuisz, T. I., Nord, A., Pénzes, J., Vargancsik, D., Vágási, C. I., Vincze, O. and Pap, P. L. (2018). How feathered are birds? Environment predicts both the mass and density of body feathers. Funct Ecol 32, 701-712.

Parr, N., Bishop, C. M., Batbayar, N., Butler, P. J., Chua, B., Milsom, W. K., Scott, G. R. and Hawkes, L. A. (2019). Tackling the Tibetan Plateau in a down suit: insights into thermoregulation by bar-headed geese during migration. J Exp Biol 222, jeb203695.

Pavlovic, G., Weston, M. A. and Symonds, M. R. E. (2019). Morphology and geography predict the use of heat conservation behaviours across birds. Functional Ecology 33, 286-296.

Petit, M. and Vézina, F. (2014). Reaction norms in natural Conditions: how does metabolic performance respond to weather variations in a small endotherm facing cold environments? PLOS ONE 9, e113617.

Petit, M., Lewden, A. and Vézina, F. (2013). Intra-seasonal flexibility in avian metabolic performance highlights the uncoupling of basal metabolic rate and thermogenic capacity. PLOS ONE 8, e68292.

Petit, M., Clavijo-Baquet, S. and Vézina, F. (2017). Increasing winter maximal metabolic rate improves intrawinter survival in small birds. Physiological and Biochemical Zoology 90, 166-177.

Pyle, P. (1997). Identification guide to North American birds, Part I: Columbidae to Ploceidae. Bolinas, CA, USA: Slate Creek Press.

R Core Team (2018). R: The R project for statistical computing. R Foundation for Statistical Computing, Vienna, Austria.

Rafferty, N. E. (2017). Effects of global change on insect pollinators: multiple drivers lead to novel communities. Current Opinion in Insect Science 23, 22-27.

Rosenmann, M. and Morrison, P. (1974). Maximum oxygen consumption and heat loss facilitation in small homeotherms by He-O2. American Journal of Physiology-Legacy Content 226, 490-495.

Saarela, S., Klapper, B. and Heldmaier, G. (1989). Thermogenic capacity of Greenfinches and Siskins in winter and summer. In Physiology of Cold Adaptation in Birds (ed. Bech, C.) and Reinertsen, R. E.), pp. 115-122. Boston, MA: Springer US.

Stager, M., Pollock, H. S., Benham, P. M., Sly, N. D., Brawn, J. D. and Cheviron, Z. A. (2016). Disentangling environmental drivers of metabolic flexibility in birds: the importance of temperature extremes versus temperature variability. Ecography 39, 787-795. 
Swanson, D. L. (1990a). Seasonal variation in cold hardiness and peak rates of cold-induced thermogenesis in the Dark-Eyed Junco (Junco hyemalis). The Auk 107, 6.

Swanson, D. L. (1990b). Seasonal variation of vascular oxygen transport in the Dark-Eyed Junco. The Condor 92, 62-66.

Swanson, D. L. (1991). Seasonal adjustments in metabolism and insulation in the Dark-Eyed Junco. The Condor 93, 538-545.

Swanson, D. L. (1993). Cold tolerance and thermogenic capacity in dark-eyed Juncos in winter: Geographic variation and comparison with American tree Sparrows. Journal of Thermal Biology 18, 275-281.

Swanson, D. L. (2010). Seasonal metabolic variation in birds: functional and mechanistic correlates. In Current Ornithology Volume 17 (ed. Thompson, C. F.), pp. 75-129. New York, NY: Springer New York.

Swanson, D. L. and Olmstead, K. L. (1999). Evidence for a proximate influence of winter temperature on metabolism in passerine biirds. Physiological and Biochemical Zoology 72, 566575.

Swanson, D. L. and Vézina, F. (2015). Environmental, ecological and mechanistic drivers of avian seasonal metabolic flexibility in response to cold winters. J Ornithol 156, 377-388.

Swanson, D. L., Thomas, N. E., Liknes, E. T. and Cooper, S. J. (2012). Intraspecific correlations of basal and maximal metabolic rates in birds and the aerobic capacity model for the evolution of endothermy. PLOS ONE 7, e34271.

Swanson, D., Zhang, Y., Liu, J.-S., Merkord, C. L. and King, M. O. (2014). Relative roles of temperature and photoperiod as drivers of metabolic flexibility in dark-eyed juncos. Journal of Experimental Biology 217, 866-875.

Therneau, T. (2015). A package for survival analysis in S. version 2.38 .

Vezina, F., Ruhs, E., O’Connor, E., Le Pogam, A., Regimbald, L., Love, O. and Jimenez, A. G. (2020). Consequences of being phenotypically mismatched with the environment: rapid muscle ultrastructural changes in cold-shocked black-capped chickadees (Poecile atricapillus). American Journal of Physiology-Regulatory, Integrative and Comparative Physiology 318, R274-R283.

Wiersma, P., Munoz-Garcia, A., Walker, A. and Williams, J. B. (2007). Tropical birds have a slow pace of life. Proceedings of the National Academy of Sciences 104, 9340-9345.

Williams, J. W. and Jackson, S. T. (2007). Novel climates, no-analog communities, and ecological surprises. Frontiers in Ecology and the Environment 5, 475-482.

Wolf, B. O. and Walsberg, G. E. (2000). The role of the plumage in heat transfer processes of birds. American Zoologist 40, 575-584. 